\title{
Ius migrandi: o direito humano previsto, mas não reconhecido d
}

\author{
Ius migrandi: the stated, but unrecognized human right
}

\author{
Luiz Rosado Costa \\ Mestre em Direito (UFMS) \\ Universidade Federal de Mato Grosso do Sul (UFMS) \\ Campo Grande, Mato Grosso do Sul, Brasil \\ E-mail: luizrosadocosta@gmail.com
}

Resumo: Em busca de melhores condições de vida, diversos trabalhadores imigrantes arriscam-se além da fronteira de seus países, ingressando ou permanecendo em outros Estados de forma irregular. Como não há o reconhecimento de um ius migrandi pela comunidade internacional, apesar de ele ser dedutível da Declaração Universal de Direitos Humanos, estes imigrantes, em geral provenientes da camada mais pobre da população, permanecem na condição de indocumentados, o que acentua sua suscetibilidade a violações de seus direitos humanos, ainda não totalmente desvinculados da cidadania. Defende-se, assim, nesta pesquisa descritiva e exploratória, através do método bibliográfico e documental que o reconhecimento do ius migrandi como direito humano é o que possibilitará o contato com a alteridade de forma igualitária, sem que o outro se encontre em situação de inferioridade em decorrência da irregularidade de seu status migratório.

Palavras-chave: Direitos Humanos. Migrações. Migrantes indocumentados. lus migrandi.

Abstract: Searching for better living conditions, several immigrant workers risk their lives crossing their own country border and entering or remaining in other states irregularly. As there is no recognition of an ius migrandi by the international community, although it is deductible from the Universal Declaration of Human Rights, these immigrants, generally from the poorest strata of the population, remain undocumented, which accentuates their susceptibility to violations of their human rights, not yet totally unrelated to citizenship. Thus, in this descriptive and exploratory research, through the bibliographic and documental method, the recognition of ius migrandi as a human right is what will enable the contact with otherness in an egalitarian way, without the other being considered in a situation of inferiority due to the irregularity of migratory status.

Keywords: Human rights. Migrations. Undocumented migrants. Ius migrandi.

Data de recebimento: $19 / 12 / 2018$

Data de aprovação: 07/02/2020

\section{Introdução}

As migrações intensificam as trocas culturais no país de destino, mas de forma subalterna, e na situação de clandestinidade na qual os imigrantes indocumentados permanecem, haverá, no máximo, um multiculturalismo caracterizado pela convivência assimétrica de culturas, sem trocas e diálogos e eles continuam como desconhecidos, o que favorece que lhes sejam impingidos o medo, a angústia e a responsabilidade por problemas estruturais da sociedade onde se encontram.

Revista Videre, Dourados, v. 12, n. 23, p. 213 a 225, jan./abr., 2020. 
Defende-se, assim, neste texto, fruto de pesquisa descritiva e exploratória, por meio do método bibliográfico e documental que o reconhecimento de um direito de migrar (ius migrandi) como direito humano é o que possibilitará o contato com a alteridade, propiciado pelos sujeitos em movimento, de forma igualitária, sem que o outro se encontre em situação de inferioridade em decorrência da irregularidade de seu status migratório.

Torna-se assim, necessário, o reconhecimento do imigrante como um interlocutor de um diálogo transcultural, construindo-se um multiculturalismo progressista e transformando a prática dos direitos humanos num projeto cosmopolita através da hermenêutica diatópica, proposta por Boaventura de Sousa Santos, que possibilitará a aproximação e diálogo entre as culturas que se encontram por intermédio dos sujeitos em movimento.

\section{Contextualização do ius migrandi como direito humano no art. 13 da Declaração Universal de Direitos Humanos}

No final do século XIX e início do século XX países europeus, como a Itália, colocavam barreiras à emigração de seus nacionais para evitar que em seus territórios ocorresse escassez de mão-de-obra. Registrou Scalabrini (2010, p. 9), em 1883, que:

Os proprietários de terra, de onde os camponeses emigram em maior número, estão preocupados com a repentina escassez de mão de obra, que se traduz num adequado aumento de pagamento para os trabalhadores que ficam e expressaram suas reclamações ao governo.

Essas reclamações geraram restrições à emigração, que gerava emigrantes clandestinos (SCALABRINI, 2010, p. 10), i.e., com situação migratória irregular no país de origem e não no de chegada. Com os regimes totalitários que se espalharam na Europa (cujos principais exemplos são Alemanha, Itália e União Soviética) continuaram a ser impostas restrições à emigração regular.

Aos europeus, não se aplicavam restrições à imigração nos países de destino, principalmente na América. Pelo contrário, sua vinda era não-raro estimulada através de políticas migratórias eugenistas (como a brasileira de "branqueamento). Em suma, os europeus não encontravam dificuldades para imigrar, mas eventualmente para emigrar e isso refletiu na maneira que o ius migrandi apareceu na Declaração Universal de Direitos Humanos de 1948: "Art. 13 [...] 2. Todo ser humano tem o direito de deixar qualquer país, inclusive o próprio, e a este regressar".

A Declaração não prevê todos os direitos humanos possíveis, mas:

Os direitos do homem histórico, tal como este se afigurava na mente dos redatores da declaração após a tragédia da Segunda Guerra Mundial, numa época que tivera início com a Revolução Francesa e desembocara na Revolução Soviética (BOBBIO, 2004, p. 20).

Assim, como documento de origem europeia que é, a preocupação nele expressa foi no sentido de vedar restrições à emigração, pois aos europeus não preocupavam as barreiras migratórias que poderiam encontrar no país de destino, mas as que eventualmente lhes eram colocadas no próprio país de origem.

O art. 13 da Declaração pode ser interpretado também como resposta às restrições à saída livre do país impostas pelos regimes totalitários europeus, que produziu elevado número de refugiados. Neste sentido, "a 
implantação de direitos com características universais, tal qual constante na Declaração, em muito estava relacionada com a política intervencionista vivida à época da Guerra Fria" (PERTILLE; PERTILLE, 2018, p. 1389).

Pode-se aventar que não houve imprecisão técnica na redação do art. 13 da DUDH ao não correlacionar expressamente o direito de emigrar com o direito de imigrar, mas uma redação eurocêntrica do ius migrandi, ao expressá-lo tal como reivindicado pelo homem europeu, a partir da premissa de que para as restrições se encontravam na origem e não no destino e removendo-as, estaria garantido o direito de livre circulação pelo globo.

Com a inversão da restrição, que hoje se encontra nos países de destino, deve-se reconhecer o direito de imigrar como consequência lógica do direito de emigrar expressamente reconhecido para assim garantir a mesma liberdade de locomoção presente na mens legis da Declaração. Mas, como ocorre com os direitos humanos em geral (BOBBIO, 2004), o problema da existência de um ius migrandi não é tanto de fundamentálo, mas de efetivá-lo, o que torna a questão mais política que jurídica.

\subsection{Migrar como direito humano}

As migrações estão presentes nos principais instrumentos internacionais de Direitos Humanos, que garantem o direito de toda pessoa sair livremente de qualquer país, como o art. 13 da Declaração Universal dos Direitos Humanos (ONU, 1948), art. 13 do Pacto de Direitos Civis e Políticos (1966), art. 8 da Declaração Americana de Direitos e Deveres do Homem (OEA, 1948) e art. 22 da Convenção Americana de Direitos Humanos (OEA, 1969).

Da interpretação do art. 13 da Declaração Universal, cujo texto inspirou os demais instrumentos internacionais de proteção aos Direitos Humanos mencionados, o professor Jesús Lima Torrado (2016) extraiu as seguintes ideias: a) os quatro critérios de interpretação jurídica formulados por Savigny permitem afirmar que o ius migrandi é, sem dúvida, um direito humano; b) a interpretação sistemática determina a necessidade de se interpretar o art. 13 em conjunto com o art. 14 (direito de asilo) e art. 22 (direitos econômicos, sociais e culturais), o que leva à mesma afirmação de que se trata de um direito humano; c) a necessidade de que a interpretação jurídica respeite os fundamentos dos direitos humanos leva a ter que reconhecer o ius migrandi como direito humano; d) a interpretação do art. 13, como de todo direito fundamental deve considerar a sua significação mais extensa, o que tem por fundamento a natureza expansiva dos direitos humanos (princípio da

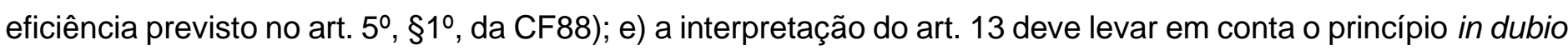
pro libertate, segundo o qual, em caso de dúvida, haverá que se estar a favor sempre do sentido mais favorável à existência e garantia de um direito fundamental.

Embora seja decorrência lógica do direito de saída de um Estado, o direito de ingresso em outro, não há o reconhecimento da existência, na atualidade ${ }^{1}$, de um ius migrandi pela comunidade internacional.

\footnotetext{
${ }^{1}$ A Constituição Brasileira de 1891, em seu art.72, §10ำ, reconhecia expressamente o ius migrandi e assegurava a livre entrada em território brasileiro, independentemente de passaporte: No mesmo sentido, os art. 4ำ da Constituição Francesa de 1793 e art. 25 da Constituição Espanhola de 1869 reconheciam o ius migrandi, permitindo que estrangeiros se estabelecem livremente nos territórios francês e espanhol.
} 
Segundo Jesús Lima Torrado (2016, p. 117): "la regulación del ius migrandi dista hoy mucho de ser satisfactoria pues se mueve - aún hoy - en la imprecisa tensión entre la soberanía del Estado y la dignidad humana".

Parte da doutrina fundamenta a prática internacional restritiva à liberdade de imigrar e defende que do art. 13 da DUDH não é possível extrair um ius migrandi (que pressupõe a entrada em outro Estado), mas apenas o direito de saída de um país. Neste sentido, Valdueza Blanco (2008, p. 53) sustenta que:

El derecho a salir surge em um contexto histórico determinado em el que la práctica de algunos Estados, normalmente de corte autoritário, negaban los visados de salida o la concesión de passaportes, por motivos políticos, siendo esta negación de derecho de salir del país uma espécie de sanción. Sin embargo, no se ha dibujado em dicha Declaración la cara opuesta, esto es, no existe obligación de acogida por parte de los países receptores, com la excepción [... del derecho e refugio y asilo. Por lo tanto los Estados gozan de uma amplia discrecionalidad em el diseño de sus políticas migratórias (BLANCO, 2008, p. 53).

No mesmo sentido, para Carrillo Salcedo (2013, p. 287), o Estado tem uma potestade superior que lhe confere o direito de determinar quem pode entrar em seu território, de tal maneira que, salvo se o Estado tenha aceito por tratados internacionais ou assim permita, não há um direito a que se escolha onde se quer viver.

Para Guofu Liu (2007, p. 72, destaque nosso)², o direito de saída não pode ser limitado pelos Estados, mas isso não significa que exista o direito de entrada em outro Estado ou a garantia de retorno, salvo para o Estado de que se é nacional:

Os Estados devem dar efeito ao direito de sair por meio da promulgação de legislação ou por outros meios. Não podem ser impostas condições ao ,como insistir que o direito é usado para uma finalidade prescrita, limitar o destino de indivíduos ou limitar o período de tempo que uma pessoa pode permanecer no exterior. No entanto, o direito de sair de um país não significa que uma pessoa tenha o direito de entrar em outro país, nem garante o direito de retorno a um país que não seja o Estado nacional.

Sem o reconhecimento do ius migrandi, todavia, o art. 13 da DUDH carece de eficácia: não é possível, na atual configuração geopolítica da Terra, que se saia de um Estado sem que automaticamente, com isso, se entre no território de outro ${ }^{3}$, i.e., os movimentos migratórios, necessariamente envolvem um local de origem e um de destino (CAMPOS, 2017) e uma pessoa será ao mesmo tempo emigrante e imigrante, a depender do Estado que se tome como referência (de origem ou destino).

Continua, assim, na esfera da soberania dos Estados a liberdade de decidir quem pode entrar e permanecer em seus territórios, ou quais imigrantes serão oficialmente aceitos e documentados e quais serão os rejeitados e indocumentados que nele poderão permanecer apenas de forma clandestina. Vedovato (2013, p. 19), todavia, ressalta que "a liberdade total do Estado para definir quem entra no seu território desapareceu com o surgimento dos tratados de direitos humanos".

\footnotetext{
2 Tradução livre de: "States should give effect to the right to leave by enacting legislation or by other means. Conditions cannot be imposed on the right, such as insisting that the right is used for a prescribed purpose, limiting the destination of individuals, or limiting the period of time that a person may remain overseas. However, the right to leave one country does not mean that a person has the right to enter another, nor does it guarantee the right of return to a country other than the national State" (LIU, 2007, p. 72).

${ }^{3}$ Neste sentido Martín (2006) destaca que se não existir o direito de imigrar, a liberdade de circulação se torna um direito de estar em órbita ou em espera.
} 
Assim, no exercício de sua soberania e liberdade de controlar suas fronteiras, os Estados podem conceder tratamento diferente aos migrantes em situação irregular — o direito de circular livremente dentro de um Estado e nele residir, por exemplo, reconhecido no Pacto de Direitos Civis e Políticos (ONU, 1966), em seu art. 12, item 1 é assegurado apenas às pessoas que se encontrem legalmente em seu território —, mas não podem agir de forma discriminatória em relação ao gozo e proteção dos Direitos Humanos e trabalhistas do migrante no local de destino. Isto porque os poderes do Estado para fixar sua política migratória estão limitados por suas obrigações de proteção aos Direitos Humanos, que não dependem do vínculo de nacionalidade, regularidade migratória ou qualquer outra circunstância.

No caso das migrações internacionais indocumentadas, amplia-se a vulnerabilidade e a necessidade de proteção pelos Direitos Humanos, pois esses migrantes sofrem uma dupla exclusão: a primeira, social, no país de origem, onde a falta de oportunidades lhes faz migrar e a segunda, de cidadania, no país de destino, onde vivem "sem existir" nos números oficiais. Não raro ainda, esses migrantes deixam-se explorar devido a sua situação irregular e o empregador sente-se livre para explorá-los por essa mesma razão, amparando-se no medo que têm de serem deportados e mantendo-os sob controle com a ameaça de entregá-los à Polícia Federal, que no Brasil é o órgão fiscalizador das migrações. A irregularidade funciona como mordaça e cria uma inversão cruel, pois é o violador de direitos e não a vítima quem se vale do poder de acionar as autoridades:

Um dos nichos de exploração do trabalho análogo ao de escravo está justamente na exploração do trabalhador imigrante, submetido a condições ilegais ou precárias, ao qual [sic] se subordinam em razão do medo da deportação e da esperança de, com o trabalho, conseguir obter dinheiro e condições futuras de legalização (SALADINI, 2012, p. 163).

Cícero Rufino Pereira (2015, p. 46) também relaciona a migração internacional de trabalhadores em situação irregular, os quais têm essa situação explorada pelos cooptadores de mão de obra escrava, com violações a seus Direitos Humanos:

Não é muito fácil aos trabalhadores "nacionais" conseguirem um trabalho decente, menos ainda os trabalhadores migrantes estrangeiros, sobretudo em uma região de fronteira. Ali (e através dela) a concorrência por mão de obra barata e por discussões acerca da legalidade ou ilegalidade da migração é pano de fundo para se perpetrarem ataques aos direitos humanos, em prol do aumento de lucros.

As migrações indocumentadas servem ainda, segundo Aloísio Krohling (2008, p. 158), à crítica da tese da universalidade dos direitos humanos:

Recentemente, decisões administrativo-jurídicas da União Europeia sobre a entrada e
permanência de imigrantes ilegais [sic] nos seus territórios tiveram repercussão negativa e
reações afirmativas das ideias-força dos direitos humanos que os próprios europeus definem e
tutelam, em seus tribunais internacionais, como universais. Não é mais um único Estado Nacional
a fechar as suas fronteiras aos "subdesenvolvidos" do Terceiro Mundo e, até, aos próprios
europeus como ciganos, albaneses e romenos, mas é a totalidade dos países-membros da União
Europeia.

Neste contexto, observa-se que os mesmos Estados que defendem a livre circulação de capital e mercadorias, defendem o aumento das restrições à circulação de pessoas que, sob o pretexto de proteger a mão de obra nacional, igualmente atende aos interesses do Mercado: a não documentação, derivada dessas restrições, gera um considerável contingente de reserva de mão de obra barata, para realizar principalmente os trabalhos sujos e pesados, sobre a qual não incidem os custos dos direitos sociais, e "descartável". 
Assim, das políticas migratórias restritivas - que apontam os imigrantes como causadores dos problemas sociais que decorrem da própria estrutura do sistema econômico neoliberal que diminui o poder do Estado em favor do Mercado e aumenta a distância entre ricos e pobres, gerando uma grande massa de excluídos - decorrem violações de Direitos Humanos, como a exploração laboral e o tráfico de pessoas, que são favorecidas pela falta de documentação.

A existência de imigrantes que se encontram de forma indocumentada, i.e., sem documentos que autorizem sua permanência em determinado Estado, per si, demonstra que não há ainda o reconhecimento, ao menos na prática, de um direito a migrar (o que dispensaria qualquer tipo de documentação ou outro requisito para que a migração se efetivasse de forma regular). As migrações, assim, exemplificam as limitações que a cidadania ainda impõe para a efetivação dos Direitos Humanos

Ao se observar a história dos direitos humanos no pós-Segunda Guerra Mundial verifica-se que suas políticas estiveram, em geral, a serviço dos interesses dos Estados capitalistas hegemônicos (SANTOS, 1997, p. 7). O não reconhecimento do ius migrandi como direito humano, apesar de logicamente dedutível de instrumentos internacionais de proteção, atente também ao interesse desses Estados, pois a indocumentação propicia uma reserva de mão-de-obra barata e descartável, sobre a qual não incidem os custos dos direitos sociais e trabalhistas.

Através do reconhecimento do ius migrandie a aplicação da hermenêutica diatópica, a interculturalidade seria uma prática que poderia favorecer os sujeitos em mobilidade e os direitos humanos exerceriam uma função contra hegemônica e emancipatória. A partir do momento em que o imigrante é tratado como "sujeito de direitos" e não apenas como um "ilegal”, podemos potenciar o intercâmbio saudável e simétrico das práticas interculturais, valorizando a multiculturalidade entre essas alteridades, que mesmo sendo simétricas, tendem à conquista e consolidação da cidadania, qual seja, um tratamento, no mínimo, mais humanizado.

\subsection{Consequências do não reconhecimento do ius migrandi: migrantes indocumentados e a ausência de "direito a ter direitos"}

A principal consequência humana do não reconhecimento do ius migrandi na prática internacional, apesar de ele ser dedutível da DUDH, são as migrações indocumentadas. Parte-se, para analisa-las, das reflexões desenvolvidas por Hannah Arendt a partir das experiências totalitárias do século XX e de sua crítica aos direitos humanos.

A filósofa alemã, na condição de judia foi vítima do nazismo e passou pelas condições de refugiada e apátrida (até se tornar cidadã dos Estados Unidos em 1951), tendo integrado as populações que analisou em seu As origens do totalitarismo - escrito entre 1945 e 1949 e lançado em 1951 — para expor o paradoxo dos direitos humanos, decorrente do fato de os direitos, embora serem decorrentes do simples pertencimento à humanidade, não são aplicados quando as pessoas estão destituídas de cidadania.

Essa sua crítica aos direitos humanos, a partir da exclusão do indivíduo da sua comunidade política, não nega os direitos humanos, mas demonstra a necessidade de sua reconstrução: “Arendt não é contrária aos 
direitos humanos, o que ela faz é um diagnóstico de sua falta de efetividade na modernidade" (TORRES, 2013, p. 121).

Hannah Arendt expõe o paradoxo dos direitos humanos, que embora sejam natos, decorrentes da condição humana, não foram/são aplicados quando as pessoas estavam/estão destituídas de cidadania. Assim, ela propõe que os direitos humanos sejam repensados como um "direito a ter direitos" (ARENDT, 1989):

Ela argumenta que esse direito não pode ser acomodado nos marcos legais de direito internacional que se centram no acordo entre Estados soberanos. Mais amplamente entendido, essa formulação denota o direito de pertencer a uma comunidade política ou de viver em uma estrutura na qual a ação, discurso e opinião de alguém sejam levados em conta (GÜNDOĞDU, 2015, p. 22, tradução nossa) ${ }^{4}$.

O direito a ter direitos deveria ser garantido pela condição humana, mas o direito internacional ainda funciona com base em acordos e tratados entre Estados soberanos sem que haja uma esfera superior à nações (ARENDT, 1989):

Para Hannah Arendt a condição essencial para o reconhecimento de um ser humano como sujeito de direito, no sistema do Direito Internacional de Direitos Humanos, deixa de ser o seu vínculo jurídico com determinado Estado ou seu status jurídico de cidadão e passa a ser sua existência como pessoa humana, seja homem, mulher ou criança (AMARAL; GUTIERREZ, 2011, $\mathrm{p}, 38)$

Destarte, a partir de sua observação da situação dos refugiados e apátridas, privados de sua personalidade jurídica propiciada pela nacionalidade, Arendt pôde constatar que a humanidade não basta para a proteção dos direitos sem que haja uma comunidade capaz de garanti-los. Dupas, Carvalho e Carvalho (2019, p. 114) destacam que:

o conceito de cidadania pode (e deve) ser ampliado conforme os acontecimentos históricos dentro de um processo civilizatório que, atrelado aos direitos humanos, faz com que restrições devam ser repudiadas.

Apesar das diferenças entre as populações tratadas por Arendt em seu estudo- migrantes forçados e apátridas - e os migrantes indocumentados que voluntariamente se arriscam em busca de novas oportunidades e possuem uma nacionalidade formal, suas críticas aos direitos humanos são também aplicáveis a esse contexto migratório (RAMJI-NOGALES, 2015).

Ter uma nacionalidade é o traço distintivo entre os apátridas, que não a têm, e os migrantes indocumentados e que confere, a estes últimos, proteção diplomática e um lugar para o qual poderão retornar - em decorrência das obrigações do Estado em relação a seus nacionais -, embora não Ihes assegure proteção e gozo de direitos, per si, no território de outro Estado. Hannah Arendt (1989, p.331) expôs o paradoxo da necessidade de pertencimento a uma comunidade nacional como condição para o gozo de direitos:

A calamidade que se vem abatendo sobre um número cada vez maior de pessoas não é a perda de direitos específicos, mas a perda de uma comunidade disposta e capaz de garantir quaisquer direitos. O homem pode perder todos os chamados Direitos do Homem sem perder a sua qualidade essencial de homem, sua dignidade humana. Só a perda da própria comunidade é que o expulsa da humanidade.

\footnotetext{
4 Tradução livre de: "She argues that this right cannot be accommodated within the framework of international law that centers the agreement among sovereign states. More broadly understood, this formulation denotes a right to belong to a political community or to live in a framework where one's action, speech, and opinion count' (GÜNDOĞDU, 2015, p. 22).
} 
O indocumentado não é, como o apátrida, privado de sua comunidade, mas esta não é capaz de garantir direitos fora do território sobre o qual exerce sua soberania: "os indocumentados não são tecnicamente apátridas, mas eles ficam em um limbo legal que remete à apatridia"5 (RAMJI-NOGALES, 2015, p. 1045, tradução nossa).

Como destacou Antônio Augusto Cançado Trindade em voto na Corte Interamericana de Direitos Humanos (OEA, 2014, p. 242), "hoje em dia, aos apátridas de jure se somam os apátridas de facto, i.e., os incapazes de demonstrar sua nacionalidade, e os desprovidos de uma nacionalidade efetiva (para os efeitos de proteção)".

A indocumentação nega acesso a direitos há muito assegurados em instrumentos internacionais como a liberdade de locomoção, unidade familiar e direitos sociais básicos como acesso a educação e saúde, mas a prática dos Estados, no exercício da soberania, condiciona o exercício desses direitos à cidadania e regularidade migratória. É negado, assim, ao indocumentado o direito a ter direitos por não possuírem uma cidadania de facto. Em outras palavras, ele tem uma cidadania (nacionalidade), decorrente do Estado de que é nacional, mas esta não lhe é aplicável no território do Estado no qual se encontra, salvo para determinar o destino de sua expulsão ou deportação.

\section{A interculturalidade favorecida pelos sujeitos em movimento}

As migrações proporcionam encontros entre sujeitos e grupos portadores de diferentes culturas, mas com a situação clandestina na qual os indocumentados permanecem haverá, no máximo, um multiculturalismo caracterizado pela convivência subalterna de culturas sem trocas e diálogos.

O imigrante continua, assim, incógnito, como um "estranho" de hábitos desconhecidos, o que favorece que sejam direcionados a eles o medo, angústia e a responsabilidade por problemas estruturais: "aproveita-se a ideologia do medo e da insegurança, culpando um outro, comumente o de pele escura e 'hábitos estranhos' por problemas que atingem a todos, não ricos, por limites estruturais do modelo político econômico" (CASTRO, 2007, p. 70-1).

Há instrumentos jurídicos que reconhecem direitos humanos aos imigrantes - o principal deles a Convenção da ONU de 1990 sobre a Proteção de Todos os Trabalhadores Migrantes e Membros de Suas Famílias - , decorrentes do processo de multiplicação de direitos humanos que considera, segundo Bobbio (2004, p. 33), o homem não mais genericamente, mas visto em sua especificidade. Esses direitos esbarram, todavia, na "vontade" dos Estados e na sua soberania para decidir quem pode ou não ingressar, permanecer (e usufruir de direitos) em seus territórios.

Neste contexto, as migrações colocam em evidência a colisão entre o direito de migrar, previsto no art. 13 da Declaração Universal de Direitos Humanos, e o direito ao autogoverno de uma comunidade política, previsto no art. 21 da mesma declaração. Expõem ainda o paradoxo dos direitos humanos que deveriam ser

5 Tradução livre de: "while undocumented migrants are not tecnically stateless, they exist in a legal limbo that recalls statelessness" (RAMJI-NOGALES, 2015, p. 1045). 
condicionados unicamente à condição humana, mas que dependem da regularidade da condição migratória, na prática, para serem reconhecidos em sua plenitude.

A indocumentação nega o acesso a direitos há muito assegurados como a liberdade de locomoção, unidade familiar e direitos sociais básicos. Condiciona-se, assim, a titularidade de direitos à cidadania e à regularidade migratória, criando-se, para eles, uma zona de sub-humanidade.

Boaventura de Sousa Santos (2014) explicita que:

Com o neoliberalismo e o seu ataque ao Estado como garante dos direitos, em especial os direitos econômicos e sociais, a comunidade dos cidadãos dilui-se ao ponto de se tornar indistinguível da comunidade humana e dos direitos de cidadania, tão trivializados como direitos humanos [...] Neste processo, os imigrantes, em especial os trabalhadores migrantes indocumentados, descem ainda mais abaixo para a "comunidade" dos sub-humanos.

Como alternativa ao impasse entre o reconhecimento legal e a condição humana, Rita Laura Segato (2006, p. 207) propõe considerar a dimensão ética da existência humana como algo distinto da moral e da lei moderna:

\begin{abstract}
Nessa concepção, o impulso ou desejo ético é visto como motor e fundamento dos direitos humanos em seu constante processo de expansão - e a marca definidora de tal impulso é a disponibilidade para a interpelação pelo outro. Para isso, muitos setores já demandam uma antropologia capaz de cumprir um novo papel e de colaborar no complicado processo de expansão do direito e de articulação entre horizontes culturais particulares e uma jurisdição que se confunde com a própria humanidade.
\end{abstract}

Essa ética propõe o reconhecimento do outro como um interlocutor de um diálogo transcultural, construindo-se um "multiculturalismo progressista" através da hermenêutica diatópica proposta por Boaventura de Sousa Santos (1997). Dessa forma, as fronteiras artificiais dos Estados estariam a serviço da cidadania e dos direitos humanos de mobilidade, de toda pessoa, qualquer que seja o motivo.

Hannah Arendt (2008) destaca em A condição humana que a subjetividade da esfera privada oferece apenas um prolongamento das perspectivas individuais e, assim, priva os homens de serem vistos e ouvidos pelos outros e de vê-los e ouvi-los, o que impossibilita uma compreensão fidedigna da realidade global e neste sentido reside a importância do contato com a alteridade:

Ser visto e ouvido por outros é importante pelo fato de que todos vêem e ouvem de ângulos diferentes. É este o significado da vida pública, em comparação com a qual até mesmo a mais fecunda e satisfatória vida familiar pode oferecer somenteo prolongamento ou a multiplicação de cada indivíduo, com os seus respectivos aspectos e perspectivas [...] mas esse "mundo" familiar jamais pode substituir a realidade resultante da soma total de aspectos apresentados por um objeto a uma multidão de expectadores. Somente quando as coisas podem ser vistas por muitas pessoas numa variedade de aspectos [...] pode a realidade do mundo manifestarse de maneira real e fidedigna. (ARENDT, 2008, p. 67, destaque nosso)

Como ressaltado, as migrações rompem o isolamento entre as culturas e propiciam o contato com a alteridade, possibilitando o diálogo entre povos que, através da hermenêutica diatópica, possibilitará a construção de uma concepção multicultural dos direitos humanos.

A hermenêutica diatópica baseia-se na concepção de que os topoi (lugares) de uma cultura são incompletos tal como a própria cultura a que pertencem, e essa incompletude é invisível do interior dessa cultura: 
O objetivo da hermenêutica diatópica não é, porém, atingir a completude - um objetivo inatingível - mas, pelo contrário, ampliar ao máximo a consciência de incompletude mútua através de um diálogo que se desenrola, por assim dizer, com um pé numa cultura e outro, noutra. Nisto reside o seu caráter diatópico (SANTOS, 1997, p. 116).

Boaventura de Sousa Santos, ao tratar da hermenêutica diatópica, frisou que "a humanidade necessita estabelecer uma globalização contra hegemônica entre os povos, por intermédio de um cosmopolitismo de relação (cosmopolitismo de insurgência, emancipatório) " (HOFFMEISTER; WOLF, 2016), propondo que o valor do ser humano venha antes dos interesses de Estados ou de conglomerados capitalistas.

Para a efetivação dos direitos humanos do migrante é necessária a aproximação intercultural e o diálogo entre culturas, mas para que eles possam ocorrer, é necessário que o ius migrandi seja reconhecido como direito humano: a consequência mais visível de seu não-reconhecimento são os migrantes indocumentados que permanecem clandestinos, estranhos à cultura local, e as trocas culturais quando ocorrem não são realizadas de forma igualitária (simétrica): o imigrante sempre estará em posição inferiorizada/subalterna.

Sousa Santos (2003, p. 28) ainda destaca que "a exclusão é sempre produto de relações de poder desiguais, que o mesmo é dizer, de trocas desiguais". Por isso a proposta de uma relação de valorização da alteridade, ver o outro como sujeito e com direito a relações igualitárias.

O ius migrandi, assim, permite que os direitos humanos possam exercer uma função contra hegemônica na medida em que visam a transformar as trocas desiguais decorrentes da (ir)regularidade migratória, em trocas interculturais.

O reconhecimento e aceitação do outro é essencial para o projeto cosmopolita de direitos humanos e a hermenêutica diatópica apresenta-se como instrumento de efetivação dos direitos humanos dos migrantes e como "antídoto" teórico-metodológico à globalização excludente e a chancela pela comunidade internacional do ius migrandi é o que possibilitará o contato com a alteridade de forma igualitária, sem que o outro se encontre em situação de inferioridade, i.e., na "zona de sub-humanidade" em decorrência da irregularidade de seu status migratório.

A cidadania, como ressaltado, ainda está relacionada à nacionalidade, mas em razão do princípio de respeito à dignidade da pessoa humana e dos instrumentos internacionais de proteção de Direitos Humanos, toda pessoa deve ter seus direitos respeitados pelo simples fato de pertencer à humanidade, independentemente de qualquer outra circunstância. Assim os Estados, a partir da vigência do sistema internacional de proteção aos Direitos Humanos, embora possam no exercício da soberania fixar suas políticas migratórias, não poderiam condicionar à regularidade migratória o gozo de Direitos Humanos fundamentais.

Conforme será demonstrado a seguir o direito de migrar é previsto nos principais instrumentos internacionais de proteção aos direitos humanos, mas ainda enseja luta por seu reconhecimento no plano fático, além do jurídico-positivo.

\section{Considerações finais}

Embora muitas vezes tratados pelas autoridades migratórias como se fossem "ilegais", os trabalhadores migrantes indocumentados não são criminosos, mas pessoas que buscam melhores condições de vida em 
Estado diverso do qual são nacionais e, com isso, almejam a mesma liberdade de locomoção já desfrutada amplamente pelo capital e pelas mercadorias.

Neste sentido, verificou-se, por meio de Hannah Arendt, a existência de um paradoxo dos direitos humanos que não foram/são aplicados quando as pessoas estavam/estão destituídas de cidadania, i.e., estão fora de uma comunidade que lhes garanta direitos e os reconheça como pessoas. Apesar de os imigrantes indocumentados não integrarem as populações tratadas por Arendt em seu estudo, suas críticas aos direitos humanos também lhes são aplicáveis, pois, apesar de terem uma nacionalidade (ao contrário dos apátridas), a situação deles se assemelha por não terem um Estado que lhes assegure proteção gozo de direitos, per si, fora de sua jurisdição nacional.

Na situação de clandestinidade na qual os imigrantes indocumentados permanecem haverá, no máximo, um multiculturalismo caracterizado pela convivência de culturas sem trocas e diálogos e eles continuam como desconhecidos, o que favorece que Ihes sejam direcionados o medo, angústia e a responsabilidade por problemas estruturais. Neste sentido, o reconhecimento do ius migrandi como direito humano possibilitará o contato com a alteridade de forma mais igualitária, sem que o outro se encontre em situação de inferioridade em decorrência da irregularidade de seu status migratório e, assim, possa ser um interlocutor multicultural, de um diálogo também ele transcultural, e que seja capaz de construir um multiculturalismo progressista, transformando a prática dos direitos humanos num projeto cosmopolita e emancipatório.

A mobilidade humana intensifica o contato com a alteridade e entre as culturas e, neste processo, o reconhecimento e aceitação do outro é essencial para o projeto cosmopolita de direitos humanos. Nesse contexto, a hermenêutica diatópica apresenta-se como instrumento de efetivação dos direitos humanos dos migrantes e como "antídoto" à globalização excludente, muitas vezes com ênfase apenas no mercado.

\section{Referências}

AMARAL, Ana Paula Martins; GUTIERREZ. José Paulo. A implementação dos direitos humanos nos sistemas jurídicos estrangeiros: uma análise de direito comparado. In: PASSOS, Jaceguara Dantas da Silva; AMARAL, Ana Paula Martins (coord.). Coletânea de direito constitucional. Campo Grande: Alvorada, 2011. p. 13-42.

ARENDT, Hannah. A condição humana. Tradução: Roberto Raposo. 10ª ed. Rio de Janeiro: Forense Universitária, 2008.

ARENDT, Hannah. Origens do totalitarismo. Tradução: Roberto Raposo. São Paulo: Companhia das Letras, 1989.

BLANCO, Maria. Dolores Valdueza. El tratamiento jurídico del trabajo de los extranjeros en España. Valladolid: Lex nova, 2008. p. 53.

BOBBIO, Norberto. A era dos direitos. Trad. Carlos Nelson Coutinho; apresentação de Celso Lafer. Rio de Janeiro: Elsevier, 2004. p. 12-39.

CAMPOS, Marden Barbosa. Migração. In: CAVALCANTI et al. [org.]. Dicionário crítico de migrações internacionais. Brasília: Editora Universidade de Brasília, 2017. p. 453-455.

CASTRO, Mary Garcia. Migração internacional: transpassando fronteiras do nacional e do individual. In:

Caderno de Debates: Refúgio, Migrações e Cidadania, n. 2, Agosto de 2007, IMDH. p. 69-75. 
DUPAS, Elaine; CARVALHO, Leonardo Chaves de; CARVALHO, Luciani Coimbra de. Para além das fronteiras: cidadania transnacional. Revista Videre, Dourados, MS, v. 11, n. 21, p. 105-120, jan./jun. 2019.

GÜNDOGDU, Ayten. Rightlessness in an age of rights: Hannah Arendt and the contemporary struggles of migrants. Oxford: Oxford University Press, 2015.

HOFFMEISTER, Guilherme Pittaluga; WOLF, Karen Emilia Antoniazzi. Migrações internacionais e hermenêutica diatópica: direitos humanos na sociedade global em rede. In: XIII SEMINÁRIO INTERNACIONAL DEMANDAS SOCIAIS E POLÍTICAS PÚBLICAS NA SOCIEDADE CONTEMPORÂNEA, 2016, Santa Cruz do Sul. Anais. Disponível em: http://online.unisc.br/acadnet/anais/index.php/sidspp. Acesso em: 12 abr. 2018.

KROHLING, Aloísio. Os Direitos Humanos na perspectiva da Antropologia Cultural. Revista de Direitos e Garantias Fundamentais. Vitória, № 3, 2008.

MARTíN, Javier de Lucas. El desorden en movimiento. In: SÁNCHEZ, Norberto Piqueras [coord.]. Geografías del desorden: migración, alteridad y nueva esfera social. Valencia: Universitat de Valencia, 2006.

ORGANIZAÇÃO DAS NAÇÕES UNIDAS. Declaração Universal dos Direitos Humanos, de 10 de dezembro de 1948. Disponível em: http://nacoesunidas.org/declaracao-universal-dosdireitos-humanos/. Acesso em: 11 abr. 2018.

ORGANIZAÇÃO DAS NAÇÕES UNIDAS. Pacto Internacional sobre Direitos Civis e Políticos, de 16 de dezembro de 1966.

Disponível em: http://www.ohchr.org/EN/Professionallnterest/Pages/CCPR.aspx\#main.

Acesso em: 12 abr. 2017.

OEA. Corte Interamericana de Direitos Humanos. Parecer Consultivo OC-21/14, de 19 de agosto de 2014, solicitado pela República Argentina, República Federativa do Brasil, República do Paraguai e República Oriental do Uruguai. Disponível em: http://www.corteidh.or.cr/docs/opiniones/seriea 21 por.pdf. Acesso em: 3 ago. 2016.

PEREIRA, Cícero Rufino. Direitos humanos fundamentais: o tráfico de pessoas e a fronteira. São Paulo: LTr, 2015.

PERTILLE, Thais Silveira; PERTILLE, Marcelo Cesar Bauer. Direitos Humanos linguísticos: O Idioma como instrumento de manutenção da dignidade humana do Imigrante. Revista Videre, Dourados, MS, v. 10, n. 19, p. 135-147, jan./jun., 2018.

RAMJI-NOGALES, Jaya. The right to have rights: undocumented migrants and State protection. Kansas Law Review, v. 63, 2015.

SALADINI, Ana Paula Sefrin. Trabalho e imigração. São Paulo: LTr, 2012.

SALCEDO, Juan Antonio Carrillo. Derechos de los inmigrantes en situación irregular en España UNED.

Teoría y Realidad Constitucional, n. 32, p. 285-291, 2013.

SANTOS, Eduardo dos. A questão migratória no mundo globalizado — brasileiros no exterior, a emigração e o retorno. In: PRADO, Erlan José Peixoto; COELHO, Renata. Migração e trabalho. Brasília: Ministério Público do Trabalho, 2015. p. 69-78.

SANTOS, Boaventura de Sousa. Poderá o direito ser emancipatório? Revista Crítica de Ciências Sociais, n. 65 , p. 3-76, maio de 2003.

SANTOS, Boaventura de Sousa. Por uma concepção multicultural de direitos humanos. Revista Lua Nova, v. 39, 1997.

SANTOS, Boaventura de Sousa. Se Deus fosse um ativista de Direitos Humanos. São Paulo. Cortez Editora, 2013 [edição digital]. 
SEGATO. Antropologia e direitos humanos: Alteridade e ética no movimento de expansão dos direitos universais. Revista Mana. Rio de Janeiro, 2006.

SCALABRINI, João Batista. A emigração italiana na América: observações. In: TOMASI, Silvano; ROSOLI, Gianfausto (org.). Scalabrini e as migrações modernas. Trad. Ivo Prati. São Paulo: CSEM, 2010. p. 5-33.

TORRADO, Jesús Lima. El problema fundamental de la emigración desde la perspectiva del sistema de derechos humanos: el debate sobre la existência del "lus migrandi". In: AGUILERA URQUIZA, Antonio H. (org.). Fronteira dos direitos humanos: direitos humanos nas fronteiras. Campo Grande: UFMS, 2016. p. 89-124.

TORRES, Ana Paula Repolês. Direito e política em Hannah Arendt. São Paulo: Edições Loyola, 2013.

VEDOVATO, Luís Renato. O direito de ingresso do estrangeiro: a circulação das pessoas pelo mundo no cenário globalizado. São Paulo: Atlas, 2013. 